\title{
Thrombin generation in mesalazine refractory ulcerative colitis and the influence of low molecular weight heparin
}

\author{
Anton A. Vrij · Ardi Oberndorff-Klein-Woolthuis · Gerard Dijkstra • \\ Andrea E. de Jong · Rob Wagenvoord · Hendrik C. Hemker · \\ Reinhold W. Stockbrügger
}

Published online: 17 February 2007

(C) Springer Science+Business Media, LLC 2007

\begin{abstract}
Background In ulcerative colitis (UC), a state of hypercoagulation has frequently been observed. Low molecular weight heparin (LMWH) has shown beneficial effects as an adjuvant treatment of steroid refractory UC in open trials. We assessed potential therapeutic effects of the LMWH reviparin in hospitalised patients with mesalazine refractory UC, as well as its influence on haemostasis factors. Methods Twentynine patients with mild-to-moderately active UC were included in a double-blind placebo controlled trial. All patients had a flare-up of disease under mesalazine treatment. Reviparin $\left(\right.$ Clivarin $^{\circledR}$ ) 3,436 IU anti-Xa/0.6 $\mathrm{ml}$ or placebo s.c. was added, and self-administered twice daily for 8 weeks. Patients were monitored for possible adverse events and changes in clinical symptoms. Endoscopical, histological, biochemical and haemostasis parameters were analysed.

Results Tolerability and compliance were excellent and no serious adverse events occurred. No significant
\end{abstract}

\footnotetext{
A. A. Vrij $(\bowtie)$

Department of Internal Medicine and Gastroenterology,

Twenteborg Hospital Almelo, Zilvermeeuw 1, PB 7600,

7600 SZ Almelo, The Netherlands

e-mail: vrijaa@zonnet.nl
}

\section{A. Oberndorff-Klein-Woolthuis · R. W. Stockbrügger Department of Gastroenterology, University Hospital Maastricht, P. Debyelaan 25, PB 5800, 6202 AZ Maastricht, The Netherlands}

\section{G. Dijkstra · A. E. de Jong}

University Medical Center Groningen, Hanzeplein 1, PB 30001, 9700 RB Groningen, The Netherlands

R. Wagenvoord · H. C. Hemker

Department of Biochemistry, Maastricht University, 6229

ER Maastricht, The Netherlands differences were observed on the clinical, endoscopical and histological outcome, as compared to placebo. A high intrinsic and extrinsic thrombin potential was found before LMWH therapy. However, the significant reduction in the thrombin generation by LMWH was not related to the reduction in disease activity.

Conclusion The LMWH reviparine reduces thrombin generation in patients with mild-to-moderately active, mesalazine refractory UC, but is not associated with a reduction in disease activity.

Keywords Low molecular weight heparin . Reviparin · Thrombin · Ulcerative colitis

\section{Introduction}

In inflammatory bowel disease (IBD), histologic and systemic signs of enhanced coagulation are well documented [1-9], and an increased risk of thromboembolic complications is well recognised in patients with ulcerative colitis (UC) and Crohn's disease (CD) [10-13]. The use of anticoagulants like low molecular weight heparin (LMWH) seems paradoxical as a therapy for a disorder characterised by bleeding. However, "fibrinoid" mucosal capillary thrombi have been detected in rectal biopsies of patients with UC [14]. As the micro-vascular thrombi were found without a clear relationship to the degree of surrounding inflammation, they might represent an association with underlying pathophysiological mechanisms [14, 15]. The finding of raised levels of plasma coagulation and fibrinolysis end-products indirectly reflects a state of hypercoagulation in patients with IBD [16]. 
More direct thrombin activity is difficult to measure, as it is a transient phenomenon during the clotting process. Currently, thrombin activity can be quantified by measuring the amount of product that is produced from an artificial thrombin substrate during coagulation. The time course of the thrombin generation curve reflects the function of the ensemble of plasmatic proand anticoagulant factors in platelet-poor plasma (PPP), as well as the procoagulant role of platelets in platelet-rich plasma (PRP) [17]. Both the extrinsic and intrinsic thrombin potential (ETP and ITP) seems to be increased in other thrombosis-prone states investigated [18, 19], but in IBD patients, the level of thrombin generation has not been reported before. As LMWH therapy may produce a benefit by affecting micro-vascular thrombi in the gut $[20,21]$, its administration could be rational in patients with UC or CDresistant to conventional forms of treatment.

The aim of this study was to clarify whether an improvement of clinical disease activity after LMWH therapy was associated with a reduced thrombin generation in patients with mild-to-moderately active UC, unresponsive to mesalazine. We additionally investigated the relationship of thrombin generation with other haemostasis factors in these patients.

\section{Methods}

\section{Patients}

In a prospective randomised double-blind placebo controlled trial, 29 patients with mild-to-moderately active mesalazine refractory UC were seen at the University Hospitals of Maastricht and Groningen, The Netherlands, and enrolled in this study from August 1996 to February 2000. The diagnosis UC was based on the Lennard-Jones criteria [22], and patients with a severity score of 4-14 according to the modified Truelove classification [23], were eligible. The active colitis could either be the first manifestation or an exacerbation of the disease. Sigmoidoscopy had to be performed less than 2 weeks before start of treatment. Excluded from the trial were patients with proven $C D$, infectious colitis, ischaemic colitis or irradiation colitis. Use of oral or rectal corticosteroids or other immunosuppressive drugs was prohibited within 4 weeks before study entry. Also excluded were patients with known thrombo-embolic disposition or current use of anticoagulants, patients with known or suspected general bleeding tendency, and patients with regular use of non-steroidal anti-inflammatory drugs or aminosalicylates. Previous adverse events to heparin therapy, known active ulcer disease, serious hepatic disease (ASAT $>3 \times$ upper limit) or renal failure (serum creatinin $>300 \mu \mathrm{mol} / 1$ ), as well as pregnancy or breastfeeding in female patients, were other exclusion criteria. Written informed consent was obtained from all patients. The ethical committees of both participating hospitals approved the protocol.

\section{Study design}

After randomisation (random allocation), the patients received either reviparin $\left(\right.$ Clivarin $^{\circledR}$ ) 3,436 IU Pharm Eur/0.6 ml (corresponding to 10,000 U of unfractionated calcium heparin) or placebo subcutaneously twice daily.

The drug and placebo were made available in individually packed disposable syringes. Both were administered through self-injection. All patients were on stable treatment with either salazopyrine $(n=4)$ or mesalazine $(n=20) 1 \mathrm{~g}$ 2-3 times daily or olsalazine $(n=5)$ in a comparable dose.

Clinical disease activity was determined by the Colitis Activity Index (CAI) [24] (from 0 to 21; severe disease defined as $>12$, inactive disease $<4$ ) on week 0 or just before treatment, and after 1,2, 4, 6 and 8 weeks of treatment. Quality of life was assessed at week 1, 4 and 8 by means of the Inflammatory Bowel Disease Questionnaire (IBDQ) [25].

The endoscopic severity of disease was scored by means of the Endoscopic Grading System [26] or EGS (from 0 to 26; severe disease $>18$ ) within 2 weeks prior to LMWH treatment. Also, a grading of histologic disease activity (HDA, from 0 to 12 ; severe inflammation >10) was performed [26]. Duplicate biopsies $(3 \mathrm{~mm})$ were taken from the most severely affected area, at $10 \mathrm{~cm}$ from the anus in the rectum and at $25 \mathrm{~cm}$ in the sigmoid. The recording of endoscopic and histological scores was done with reference to the most inflamed site in the colon or rectum. The EGS and HDA score were repeated after 8 weeks of treatment, and one experienced pathologist assessed all biopsies in a blinded manner.

At regular intervals (week 0 or just before treatment, and after 1, 2, 4, 6 and 8 weeks of treatment), laboratory tests were performed: the erythrocyte sedimentation rate, red and white blood cell counts, platelet counts (normal values: $130-350 \times 10^{9} / 1$ ), mean platelet volume (MPV; 8.6-9.7 fl), platelet distribution width (PDW; $15-18 \%$ ), serum levels of C-reactive protein (CRP; 0-9 mg/l), alkaline phosphatase (AP; 30-125 IU/l), gamma-glutamyl-transpeptidase (GGT; 10-50 IU/1), lactate dehydrogenase (100-250 IU/1), and serum levels of aspartate aminotransferase (AST; 5-40 
IU/l) and alanine aminotransferase (ALT; 5-40 IU/l) and creatinin (creat; 40-90 $\mu \mathrm{mol} / \mathrm{l}$ ).

Different markers of coagulation like the APTT (24$35 \mathrm{~s}$, thrombin-antithrombin complex (TAT; 0.00-1.90 $\mu \mathrm{g} / \mathrm{ml}$ ), prothrombin fragment 1 and 2 (F1.2; $0.40-1.45$ $\mathrm{nmol} / \mathrm{l})$, as well as anti-IIa activity $(0.0-0.07 \mathrm{U} / \mathrm{ml})$, antiXa activity $(0.0-0.02 \mathrm{U} / \mathrm{ml})$ and the ITP and ETP were determined. Treatment was intended to last 8 weeks. Control visits were planned at 1, 2, 4, 6 and 8 weeks.

Treatment was discontinued if there was no improvement after 4 weeks according to the CAI [24], or in any patient with progression of disease activity at any control visit. Other predefined reasons for discontinuation were heparin-induced thrombocytopenia (HIT) type $2[27,28]$ and/or severe bleeding (defined as $\mathrm{Hb}<5.0 \mathrm{mmol} / \mathrm{l}, \mathrm{Hb}>2.0 \mathrm{mmol} / \mathrm{l}$ below baseline value, blood loss with blood pressure $<80 / 50$ $\mathrm{mmHg}$ and/or need for blood transfusion). In patients in whom the study treatment was discontinued, a treatment with corticosteroids was initiated.

\section{Preparation of plasma}

The collection of blood was strictly timed, i.e. $30 \mathrm{~min}$ before the next dose of LMWH in the morning, and 30 min before laboratory analysis started.

Fresh citrated blood (nine parts of blood to one part of $0.13 \mathrm{~mol} / 1$ trisodiumcitrate) was centrifuged at $250 \mathrm{~g}$, $15^{\circ} \mathrm{C}$ for $10 \mathrm{~min}$. The platelet count was adjusted to $3 \times$ $10^{8} / \mathrm{ml}$ using autologous PPP, made by double centrifugation of PRP at $1,000 \mathrm{~g}, 15^{\circ} \mathrm{C}$ for $10 \mathrm{~min}$. Before storage at $-80^{\circ} \mathrm{C}$, PPP was centrifuged twice at $1,000 \mathrm{~g}$ for $10 \mathrm{~min}$. Plasma was defibrinated by adding 1/50 volume of Ancrod and clot dissolution. After the thrombin generation test had been performed, the remaining serum was put on ice and centrifuged at $15,000 \mathrm{~g}$ for $2 \mathrm{~min}$. The supernatant was stored at $-80^{\circ} \mathrm{C}$. Normal pool plasma was pooled PPP from at least ten apparently healthy male and female donors and stored at $-80^{\circ} \mathrm{C}$ for less than 4 months.

\section{Measurement of thrombin generation}

Thrombin generation was measured with a subsampling technique, as previously described in detail [1719], either triggered by tissue factor (extrinsically) or by contact activation (intrinsically). In short, thrombin was determined by monitoring optical density of the pNA at $405 \mathrm{~nm}$, released from a slow-reacting chromogenic thrombin substrate (DEMZ-Gly-Arg-pNA) which was added to the defibrinated plasma upon recalcification. The reacting mixture for the measurement of thrombin generation consisted of one part of buffer containing phospholipid vesicles $(20 \mathrm{~mol} \%$ phosphatidylserine and $80 \mathrm{~mol} \%$ phosphatidylcholine).

For the extrinsic system, $4 \mu \mathrm{M}$ phospholipid with 15 pM recombinant human tissue factor was added, and for the intrinsic system $4 \mu \mathrm{M}$ phospholipid and $1 / 6$ volume of Actin-FSL (Dade Behring ${ }^{\circledR}$ ). The ETP and ITP level is expressed as a percentage of the ETP and ITP of normal pool plasma, measured simultaneously. The mean value of ETP in PPP in healthy controls was $737 \mathrm{nmol} / 1 \mathrm{~min}$ (range 720-790), the mean ITP level in PPP in healthy controls was $798 \mathrm{nmol} / \mathrm{l}$ min (range 780-850) [29, 30]. The normal values of ETP, ITP, as well as TAT and F1.2, were obtained from ten healthy controls (five male, five female), and were compared with the values of the patients.

\section{Statistical analysis}

The sample size of the clinical trial was based on categorical data ("did the patient improve?"). For the expected proportion with specified outcome was chosen: $\mathrm{p}_{1}=$ improved on LMWH $0.80, \mathrm{p}_{2}=$ improved on placebo 0.20. The calculated SD was 1.2. Taking the power to be 0.85 and a one-sided significance level of 0.05 , the sample size was calculated to be 24 for each group. Analysis was performed on an intention-to-treat basis with last value carried forward in case of premature discontinuation. To test differences for significance, the Mann-Whitney-Wilcoxon rank-sum test was performed. A Bonferroni adjustment was used for multiple comparisons, and an alpha level of 0.017 was considered significant with tests performed at 0,4 and 8 weeks [31]. Also, the Spearman rank correlation coefficient and the two-tailed significance of the correlation were calculated between the coagulation factors and other biochemical and disease parameters. SPSS 13.0 software (SPSS Inc., USA) was used for statistical analysis.

\section{Results}

\section{Patients}

Fifteen patients were randomised to receive the LMWH reviparin and 14 to receive placebo (19 patients were studied in the University Hospital Maastricht and 10 in the University Hospital Groningen). Demographic data and clinical characteristics of patients randomised to treatment are shown in Table 1. There was no difference between the two groups with regard to age, gender, smoking habits or disease severity as measured by CAI. Mean duration 
Table 1 Baseline characteristics of placebo and reviparin-treated patients

\begin{tabular}{llll}
\hline & Placebo & Reviparin & Significance \\
\hline Number of patients & 14 & 15 & $\mathrm{~ns}$ \\
Age (mean) & 42 & 38 & $\mathrm{~ns}$ \\
Sex (M/F) & $7 / 7$ & $9 / 6$ & $\mathrm{~ns}$ \\
Smoking (previous/never) & $1(11 / 2)$ & $3(8 / 4)$ & $\mathrm{ns}$ \\
Previous steroid use & 9 & 9 & $\mathrm{~ns}$ \\
CAI (min-max) & $9(3-13)$ & $10(5-16)$ & $\mathrm{ns}$ \\
Duration of disease & $7(0-26)$ & $6(0-15)$ & $\mathrm{ns}$ \\
$\quad$ in years (range) & & & \\
\hline
\end{tabular}

$n s$ not significant

and extent of disease, previous steroid treatment and individual or family history of thrombosis or bleeding tendency were similar in both groups.

Influence of additional LMWH treatment on the CAI, IBDQ, EGS and HDA

In the reviparin group $11 / 15(73.3 \%)$ patients completed the 8 weeks of treatment, in the placebo group $9 / 14(64.3 \% ; p=0.70)$. One patient in the placebo group was lost to follow-up after 2 weeks. In all other patients, reason for discontinuation was either lack of efficacy or exacerbation. At 8 weeks the improvement in CAI was 3.80 points in the reviparin group and 2.08 points in the patients treated with placebo $(p=0.20)$. In the reviparin group $12 / 15(80 \%)$ patients had improved, compared to $11 / 13(85 \%)$ in the placebo group $(p=1.0)$.

There were no significant differences in IBDQ, ESG, or HDA between both groups (Table 2).

Haemostasis characteristics and the influence of LMWH treatment on thrombin generation, haemostasis and fibrinolysis factors at baseline, at 4 and at 8 weeks

At baseline, patients in the LMWH group had above normal levels of ETP $(777 ; 171)$ and ITP $(824 ; 188)$ $(p=0.02)$. Also, patients in the placebo group had higher levels of ETP (784; SD 87) and ITP (833; SD $100)$, than the normal control values of ETP $(737 ; 19$ with $p<0.001)$, and ITP $(798 ; 19$ with $p<0.01)$.

At baseline, TAT and F1.2 were significantly raised in the LMWH and placebo group, compared to the healthy controls $(p<0.0001$ and $p<0.0001$ respectively). The APTT, the anti-IIa and the anti-Xa activity was within normal limits in the LMWH and placebo group.

At 4 weeks, the ETP and ITP values were significantly lower in the LMWH-treated group, as compared to the placebo group ( $p=0.014$ and 0.015$)$, as well as the healthy controls $(p=0.001$ and 0.001$)$. However, TAT and F1.2 levels were higher, both in the LMWH group $(p<0.0001$ and $p=0.004)$ and placebo group $(p<0.0001$ and $p=0.004)$, as compared to the healthy controls. Also, anti-IIa $(p<0.0001)$ and anti-Xa activity $(p<0.0001)$, as well as APTT $(p=0.007)$ and ALT levels $(p=0.008)$, were significantly higher in the LMWH-treated patients, as compared to placebo.

At 8 weeks, the ETP and ITP values were not significantly lower in the LMWH-treated group, as compared to the placebo group ( $p=0.536$ and 0.887$)$, or the healthy controls ( $p=0.238$ and $p=0.892)$. However, TAT $(p<0.0001)$ and F1.2 $(p=0.039)$ were higher in the placebo group, as well as was TAT in the LMWH group $(p<0.0001)$, as compared to the healthy controls.

Also, the anti-Xa activity, but not the anti-IIa, APTT or ALAT levels, was significantly higher at 8 weeks in the LMWH-treated patients, as compared to placebo $(p=0.002)$. Table 3 summarises the differences of laboratory data between the reviparin and placebo-treated groups. The time course of ETP and ITP is shown in Figs. 1 (reviparin) and 2 (placebo). The time course of TAT and F1.2 is shown in Figs. 3 (reviparin) and 4 (placebo). The box-whisker plots represent the median (line between the 25th and 75th percentile box) and min-max values (whisker lines extended from the box as smallest and largest values), as well as outliers $\left({ }^{0}\right)$ and extremes $(*)$.

Table 2 Clinical (CAI, IBDQ), endoscopical (EGS) and histological (HDA) activity indices, before and after reviparin therapy or placebo, are shown

\begin{tabular}{lllllll}
\hline & \multicolumn{2}{l}{ Placebo } & & \multicolumn{2}{l}{ Reviparin } \\
\cline { 2 - 3 } \cline { 6 - 7 } & Week 0 & Week 4 & Week 8 & & Week 0 & Week 4 \\
\hline CAI & $9.1[3.1]$ & $7.3[3.2]$ & $5.8[3.1]$ & $9.9[2.9]$ & $6.7[3.5]$ & Week 8 \\
IBDQ & $147[24]$ & $154[25]$ & $167[23]$ & $133[30]$ & $5.1[3.5]$ \\
EGS & $9.5[3.3]$ & Not done & $7.3[5.3]$ & $9.6[3.2]$ & Not done & $7.4[4.3]$ \\
HDA & $3.9[2.1]$ & Not done & $3.1[2.5]$ & $2.9[1.8]$ & Not done \\
\hline
\end{tabular}

Means and standard deviations ([ ] between the groups with reviparin and those with placebo are presented at week 0,4 and 8 . No significant differences were found between these groups 
Table 3 Laboratory data with means, standard deviations ([ ] ) and significant differences $(* p<0.017)$ between the groups treated with reviparin or placebo, at weeks 0,4 and 8

\begin{tabular}{|c|c|c|c|c|c|c|}
\hline & \multicolumn{3}{|l|}{ Placebo } & \multicolumn{3}{|l|}{ Reviparin } \\
\hline & Week 0 & Week 4 & Week 8 & Week 0 & Week 4 & Week 8 \\
\hline \multicolumn{7}{|l|}{ Biochemistry } \\
\hline CRP (mg/l) & $11.4[16.2]$ & $11.2[12.0]$ & $18.9[19.5]$ & $16.0[18.2]$ & 10.4 [13.0] & $20.8[36.8]$ \\
\hline Albumin (g/l) & $40.3[5.4]$ & $40.5[4.7]$ & $40.7[4.2]$ & $40.3[4.6]$ & $41.3[6.5]$ & $41.4[3.6]$ \\
\hline ALT (IU/l) & 18.6 [6.2] & $20.0[6.4]$ & $18.0[6.5]$ & $26.1[26.2]$ & $35.3[18.9]^{*}$ & 24.8 [13.2] \\
\hline \multicolumn{7}{|l|}{ Platelets } \\
\hline Number $\left(10^{9} / 1\right)$ & $276[60]$ & 280 [81] & 285 [77] & $275[66]$ & $274[65]$ & 286 [71] \\
\hline MPV (fl) & $8.0[0.9]$ & $7.9[0.7]$ & $7.8[1.1]$ & $7.7[1.0]$ & $7.8[0.6]$ & $7.8[0.6]$ \\
\hline PDW (\%) & $16.4[0.7]$ & $16.5[0.3]$ & $16.6[0.3]$ & $16.5[0.5]$ & $16.3[0.6]$ & $16.5[0.3]$ \\
\hline \multicolumn{7}{|l|}{ Coagulation } \\
\hline APTT (s) & 31.4 [3.9] & $30.6[3.0]$ & $31.7[4.4]$ & $32.7[4.5]$ & $35.3[4.7]^{*}$ & $36.3[5.2]$ \\
\hline TAT $(\mu \mathrm{g} / \mathrm{ml})$ & $3.61[2.19]$ & $5.23[8.29]$ & $2.63[0.65]$ & $6.73[9.09]$ & 7.44 [17.13] & $2.47[1.48]$ \\
\hline F1.2 (nmol/l) & $1.29[0.45]$ & $1.53[0.62]$ & $1.40[0.45]$ & $2.26[2.40]$ & $1.92[2.12]$ & $1.29[0.52]$ \\
\hline ETP (nmol/l min) & 784 [87] & 743 [115] & $767[73]$ & 777 [171] & $598[172]^{*}$ & 722 [183] \\
\hline ITP (nmol/1 min) & $833[100]$ & 815 [99] & 782 [79] & 824 [188] & $613[211]^{*}$ & $793[256]$ \\
\hline Anti-IIa (U/ml) & $0.043[0.034]$ & $0.053[0.038]$ & $0.064[0.025]$ & $0.038[0.023]$ & $0.135[0.057]^{*}$ & $0.095[0.052]$ \\
\hline Anti-Xa (U/ml) & $0.006[0.009]$ & $0.008[0.006]$ & $0.007[0.005]$ & 0.013 [0.019] & $0.552[0.173]^{*}$ & $0.334[0.271]^{*}$ \\
\hline
\end{tabular}

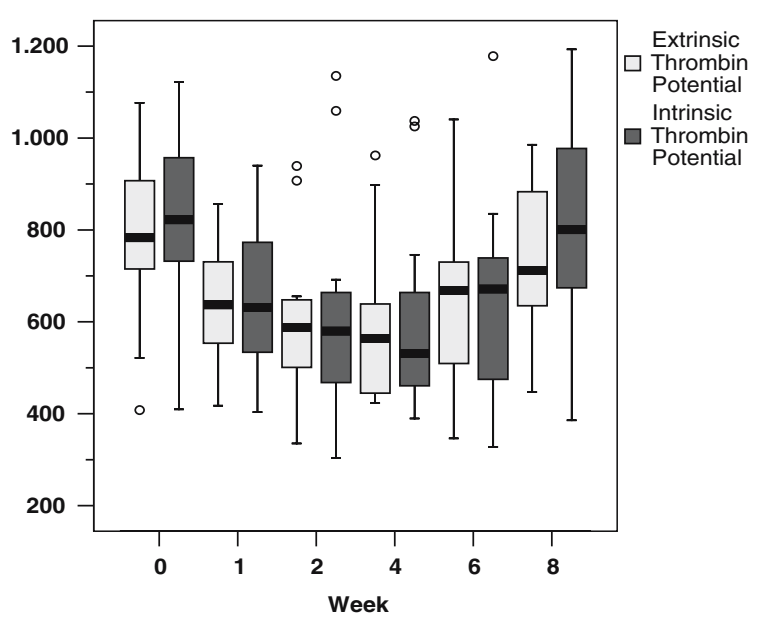

Fig. 1 Box-whisker plots of ETP and ITP (nmol/1 min; normal mean values of ETP and ITP are 737 and 798), during 8 weeks of follow-up in patients with UC, treated with mesalazine and reviparin

Relationship between haemostasis parameters and CAI, CRP, endoscopic and histologic parameters

In the placebo-treated patients, the clinical activity score CAI was positively correlated with the ITP $(r=0.267$; $p=0.038)$, as well as platelet count $(r=0.506 ; p<$ $0.0001)$ and APTT ( $r=0.336 ; p=0.007)$, and inversely correlated to PDW ( $r=-0.552$; Spearman's rho, twotailed significance $p<0.0001)$. CRP correlated positively with ETP $(r=0.531 ; p<0.0001)$, ITP $(r=0.664 ; p<$ $0.0001)$ and anti-Xa $(0.336 ; p=0.007)$, and inversely with MPV $(r=-0.361 ; p=0.002)$ and PDW $(r=-0.382$;

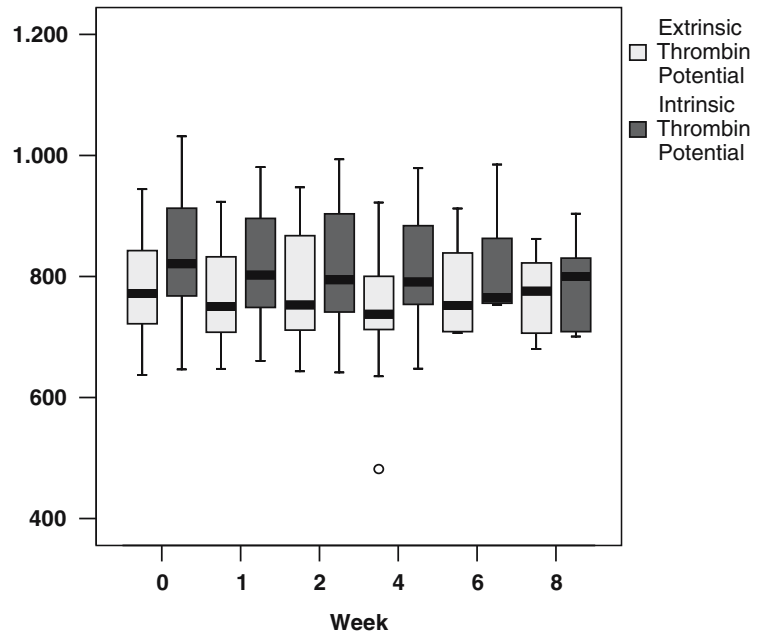

Fig. 2 Box-whisker plots of ETP and ITP (nmol/1 min; normal mean values of ETP and ITP are 737 and 798), during 8 weeks of follow-up in patients with UC, treated with mesalazine and placebo

$p=0.018)$. The endoscopy and histology score EGS and HDA did not correlate with the haemostasis parameters in the placebo group.

In the LMWH-treated group, CAI correlated inversely with MPV $(r=-0.293 ; p=0.008)$, and inversely with the APTT $(r=-0.271 ; p=0.016)$. CRP correlated with platelet count $(r=0.344 ; p=0.001)$, $\operatorname{ETP}(r=0.472 ; p<0.0001), \operatorname{ITP}(r=0.491 ; p<0.0001)$, TAT $(r=0.283 ; p=0.014)$ and APTT $(r=0.315$; $p=0.004)$. The EGS did not correlate with ETP, and the HDA correlated inversely with ETP $(r=-0.456$; $p=0.029$ ). 


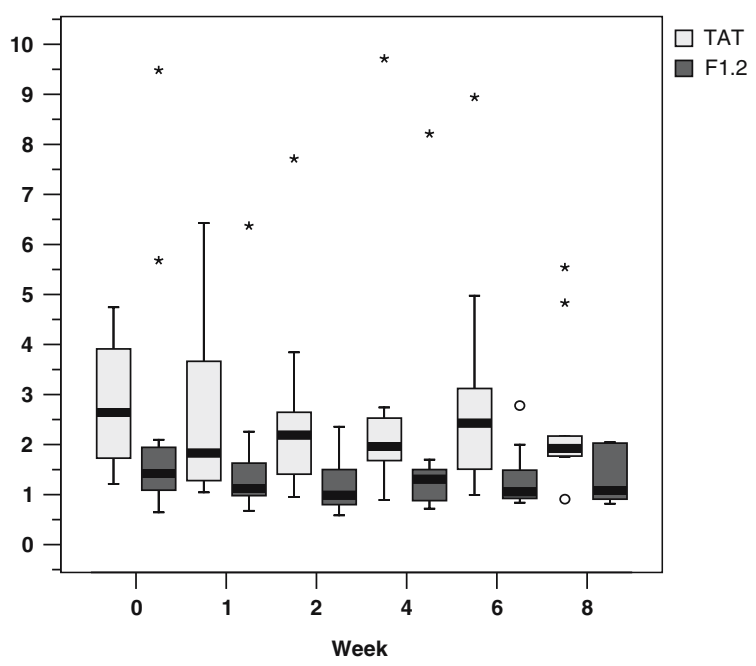

Fig. 3 Box-whisker plots of TAT ( $\mu \mathrm{g} / \mathrm{ml}$; normal upper limit 1.90 $\mu \mathrm{g} / \mathrm{ml}$ ) and F1.2 (nmol/l; normal upper limit $1.45 \mathrm{nmol} / \mathrm{l}$ ) during 8 weeks of follow-up in patients with UC, treated with mesalazine and reviparin

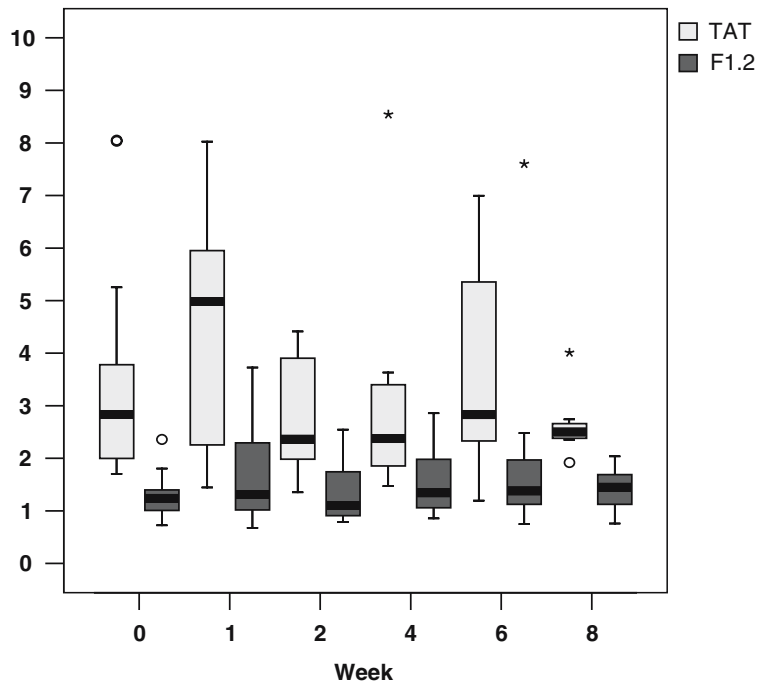

Fig. 4 Box-whisker plots of TAT ( $\mu \mathrm{g} / \mathrm{ml}$; normal upper limit 1.90 $\mu \mathrm{g} / \mathrm{ml}$ ) and F1.2 (nmol/l; normal upper limit $1.45 \mathrm{nmol} / \mathrm{l}$ ) during 8 weeks of follow-up in patients with UC, treated with mesalazine and placebo

\section{Discussion}

To our knowledge, this is the first study to present data on direct thrombin generation in patients with UC. The study demonstrates that the thrombin potential, both intrinsic and extrinsic, is above the norm in patients with active UC, confirming more indirect data on hypercoagulation in these patients [16]. The administration of LMWH diminished the ITP and ETP in patients with $\mathrm{UC}$, comparative to the effect of $\mathrm{LMWH}$ on patients with active thrombo-embolic diseases $[18,30,32]$.

In the reviparin-treated group, the anti-IIa activity and APTT were raised after 4 weeks of treatment. However, both normalised after 8 weeks, while the anti-Xa activity was still raised. Although we did not find a clear explanation for the gradual loss of anti-IIa activity in our patients, a more selective LMWH anti$\mathrm{Xa}$ activity was expected from literature [20]. Surprisingly, the administration of a therapeutic dose of reviparin was accompanied by a rise in the thrombin potential at week 8 , not different from baseline levels.

On the one hand, this questions the effectiveness of selective anti-Xa blocking agents on reducing the thrombin potential over time in patients with UC. The size of the effect on thrombin generation might depend on the type of activation used to initiate the clotting, which could be dependent of higher amounts of tissue factor [33].

On the other hand, the scheduled dose of reviparin $(3,436 \mathrm{IU} / 12 \mathrm{~h})$ corresponds to $10,000 \mathrm{IU} / 12 \mathrm{~h}$ of unfractionated heparin, and this might be considered as an intermediate dose.

We do not know if a higher dose (e.d. 15,000 IU/ 12h) would be effective in improving the clinical outcomes of UC, as the reached anti-Xa plasma level at 8 weeks was below the generally accepted therapeutic range of $0.4-1.0 \mathrm{aXa} \mathrm{IU} / \mathrm{ml}$.

No correlation was found between the (level of) reduction of the thrombin potential and both clinical (CAI; IBDQ), endoscopy and histology scores. However, a positive correlation was found between ETP and ITP with CRP, suggesting a pattern of acute phase reactivity in thrombin generation. The more stable end-products F1.2 and TAT did not correlate with CAI and CRP in the placebo-treated patients and this might favour the use of ITP or ETP as indices of UC disease activity over that of F1.2 and TAT.

No additional benefit of reviparin was found compared to the placebo-treated patients, on CAI, IBDQ, EGS and HDA. This is in contrast with the positive results found in a previous but open study done with nadroparin, in corticosteroid-resistant UC patients [15]. It suggests that $\mathrm{LMWH}$, in combination with aminosalicylates but in the absence of corticosteroids, does not have any therapeutic advantage above a placebo, as was recently also shown by other investigators [34].

A masking effect due to the use of aminosalicylate therapy remains possible, although 8 weeks of therapy should have led to induction of remission. Also, the 8 -week observation period following LMWH and placebo might have been too short to evaluate if a 
reduced thrombin generation has any influence with respect to the HDA score. However, the combination of LMWH and corticosteroids did reduce the HDA score significantly within 8 weeks of therapy in a previous study [15].

Regrettably, the number of subjects needed to reach statistical power was not met in this study, because of slow recruitment.

Also, the placebo response in this patient group was above $60 \%$, and was much higher than the $20 \%$ anticipated. These factors may have contributed to lacking evidence for benefit of LMWH treatment on clinical, endoscopy and histology outcomes in patients with mildto-moderately active UC.

Also, patients with known arterial or venous thrombo-embolic complications were excluded to overcome the bias of having an underlying tendency of hypercoagulation, unrelated to UC. However, data from open trials showed that LMWH therapy can reduce colitis activity in patients with active thrombosis, and these could have been patients to most benefit from LMWH treatment.

To prevent thrombo-embolic complications frequently seen in patients with UC, the use of an LMWH seems logical, as it reduces the state of hypercoagulation as was present in our patients at baseline. A higher dose of reviparin could be necessary to effectively reduce the thrombin potential in these patients over time periods longer than 4 weeks. This phenomenon of therapeutic "resistance," or possibly tachyphylaxis, needs further investigation.

With the reviparin doses used we observed a temporary rise in the liver ALT level, a known side effect of heparin treatment [35], also reported in a previous study on LMWH in UC [15]. Fortunately, as in other studies [15, 34], no serious bleeding complications were encountered, suggesting that LMWH is a relatively safe drug in this patient group with tendency for mucosal bleeding.

In conclusion, in patients with mild to moderate UC, the addition of the LMWH reviparin to mesalazine did not change clinical outcome; it reduces the thrombin potential and might therefore prevent thrombo-embolic complications in these patients.

Acknowledgments The study was performed at the departments of Gastroenterology and Hepatology at the University Hospital Maastricht, Maastricht, The Netherlands, as well as the University Medical Center, Groningen, The Netherlands. Coagulation studies were done at the Haematology and Biochemistry laboratory departments at the University Hospital Maastricht. Knoll Pharma supplied the study medication reviparin $\left(\right.$ Clivarin $\left.^{\circledR}\right)$, but was not directly involved in study funding.

\section{References}

1. Lam A, Borda IT, Inwood MJ, Thomson S (1975) Coagulation studies in ulcerative colitis and Crohn's disease. Gastroenterology 68(2):245-251

2. Lake AM, Stauffer JQ, Stuart MJ (1978) Hemostatic alterations in inflammatory bowel disease: response to therapy. Am J Dig Dis 23(10):897-902

3. Wakefield AJ, Sawyerr AM, Dhillon AP et al (1989) Pathogenesis of Crohn's disease: multifocal gastrointestinal infarction. Lancet 2(8671):1057-1062

4. van Wersch JW, Houben P, Rijken J (1990) Platelet count, platelet function, coagulation activity and fibrinolysis in the acute phase of inflammatory bowel disease. J Clin Chem Clin Biochem 28(8):513-517

5. Wakefield AJ, Sankey EA, Dhillon AP et al (1991) Granulomatous vasculitis in Crohn's disease. Gastroenterology 100(5 Pt 1):1279-1287

6. Webberley MJ, Hart MT, Melikian V (1993) Thromboembolism in inflammatory bowel disease: role of platelets. Gut 34(2):247-251

7. Souto JC, Martinez E, Roca M et al (1995) Prothrombotic state and signs of endothelial lesion in plasma of patients with inflammatory bowel disease. Dig Dis Sci 40(9):18831889

8. Collins CE, Rampton DS, Rogers J, Williams NS (1997) Platelet aggregation and neutrophil sequestration in the mesenteric circulation in inflammatory bowel disease. Eur $\mathbf{J}$ Gastroenterol Hepatol 9(12):1213-1217

9. Vrij AA, Rijken J, Van Wersch JW, Stockbrugger RW (2000) Platelet factor 4 and beta-thromboglobulin in inflammatory bowel disease and giant cell arteritis. Eur J Clin Invest 30(3):188-194

10. Graef V, BA, Sauer W, Spittell J (1966) Venous thrombosis occurring in nonspecific ulcerative colitis: a necropsy study. Arch Intern Med 117:377-382

11. Braverman D, Bogoch A (1978) Arterial thrombosis in ulcerative colitis. Am J Dig Dis 23(12):1148-1150

12. Talbot RW, Heppell J, Dozois RR, Beart RW Jr (1986) Vascular complications of inflammatory bowel disease. Mayo Clin Proc 61(2):140-145

13. Bernstein CN, Blanchard JF, Houston DS, Wajda A (2001) The incidence of deep venous thrombosis and pulmonary embolism among patients with inflammatory bowel disease: a population-based cohort study. Thromb Haemost 85(3): 430-434

14. Dhillon AP, Anthony A, Sim R et al (1992) Mucosal capillary thrombi in rectal biopsies. Histopathology 21(2): 127-133

15. Vrij AA, Jansen JM, Schoon EJ, de Bruine A, Hemker HC, Stockbrugger RW (2001) Low molecular weight heparin treatment in steroid refractory ulcerative colitis: clinical outcome and influence on mucosal capillary thrombi. Scand J Gastroenterol Suppl 234:41-47

16. Vrij AA, Rijken J, van Wersch JW, Stockbrugger RW (2003) Coagulation and fibrinolysis in inflammatory bowel disease and in giant cell arteritis. Pathophysiol Haemost Thromb 33(2):75-83

17. Hemker HC, Beguin S (1995) Thrombin generation in plasma: its assessment via the endogenous thrombin potential. Thromb Haemost 74(1):134-138

18. Wielders S, Mukherjee M, Michiels J et al (1997) The routine determination of the endogenous thrombin potential, first results in different forms of hyper- and hypocoagulability. Thromb Haemost 77(4):629-636 
19. Faber CG, Lodder J, Kessels F, Troost J (2003) Thrombin generation in platelet-rich plasma as a tool for the detection of hypercoagulability in young stroke patients. Pathophysiol Haemost Thromb 33(1):52-58

20. Hirsh J (1991) Heparin. N Engl J Med 324(22):1565-1574

21. Korzenik J (1997) IBD: a vascular disorder? The case for heparin therapy. Inflamm Bowel Dis 3(2):87-94

22. Lennard-Jones JE (1989) Classification of inflammatory bowel disease. Scand J Gastroenterol Suppl 170:2-6; discussion $16-19$

23. Vrij AA, Rijken J, van Wersch JW, Stockbrugger RW (1999) Differential behavior of coagulation factor XIII in patients with inflammatory bowel disease and in patients with giant cell arteritis. Haemostasis 29(6):326-335

24. Lichtiger S, Present DH, Kornbluth A et al (1994) Cyclosporine in severe ulcerative colitis refractory to steroid therapy. N Engl J Med 330(26):1841-1845

25. Guyatt G, Mitchell A, Irvine EJ et al (1989) A new measure of health status for clinical trials in inflammatory bowel disease. Gastroenterology 96(3):804-810

26. Deventer S, Roskam H, Mul M et al (2001) Prospective randomized open-label blinded endpoint (PROBE) trial of high- versus low-dose mesalazine for prevention of relapse in patients with ulcerative colitis in remission. Gastroenterology 120:A454

27. Biegholdt M (1989). Descriptive analysis of the European Fraxiparin Study. Semin Thromb Hemost 15(4):409-413

28. Schwartz KA, Royer G, Kaufman DB, Penner JA (1985). Complications of heparin administration in normal individuals. Am J Hematol 19(4):355-363
29. Hemker HC, Giesen P, Al Dieri R et al (2003) Calibrated automated thrombin generation measurement in clotting plasma. Pathophysiol Haemost Thromb 33(1):4-15

30. Vanschoonbeek K, Feijge MA, Van Kampen RJ et al (2004) Initiating and potentiating role of platelets in tissue factorinduced thrombin generation in the presence of plasma: subject-dependent variation in thrombogram characteristics. J Thromb Haemost 2(3):476-484

31. Sankoh AJ, Huque MF, Dubey SD (1997) Some comments on frequently used multiple endpoint adjustment methods in clinical trials. Stat Med 16(22):2529-2542

32. Al Dieri R, Alban S, Beguin S, Hemker HC (2004) Thrombin generation for the control of heparin treatment, comparison with the activated partial thromboplastin time. J Thromb Haemost 2(8):1395-1401

33. Baier K, Cvirn G, Fritsch P et al (2005) Higher concentrations of heparin and hirudin are required to inhibit thrombin generation in tissue factor-activated cord plasma than in adult plasma. Pediatr Res 57(5 Pt 1):685-689

34. Bloom S, Kiilerich S, Lassen MR et al (2004) Low molecular weight heparin (tinzaparin) vs. placebo in the treatment of mild to moderately active ulcerative colitis. Aliment Pharmacol Ther 19(8):871-878

35. Olsson R, Leonhardt $\mathrm{T}$ (1991) Cholestatic liver reaction during heparin therapy. J Intern Med 229(5):471-473 